Aarrevaara, T., Wikström, J., \& Maassen, P

\title{
External stakeholders and internal practices in departments of teacher education
}

Flagship universities are research universities operating in an environment of conflicting goals and priorities. Their status in research as well as education is dependent on their performance in various global arenas where performance can be identified with relatively clear indicators. However, success in operations outside the primary tasks of the academic community, such as universities' societal relevance, is more difficult to identify. Tasks outside the core of academic work are subject to requirements that are less well defined and are more abstract. This article seeks to define these non-core requirements as external contingencies and to analyse them by means of a contingency theory approach.

Keywords: departments of teacher education, contingency theory, strategy, performance

\section{Introduction}

In this article we will discuss specific findings of the Flagship research project, which was aimed at examining how large, traditional, comprehensive universities in a number of European countries interpret and use their enhanced institutional autonomy internally, with a focus on the departmental level of these universities ${ }^{1}$. The findings presented and discussed here are in the area of teacher education, and are based on case studies in three teacher education departments at the Universities of Oslo (Norway), Helsinki (Finland), and KU Leuven (Belgium).

Teacher education as an academic field has undergone several changes when it comes to its academic organisation and the ways it is embedded in higher education systems and institutions, as well as how it relates to professional practices. The field has been deemed increasingly relevant for the quality of national primary and secondary education systems, while at the same time it has evolved into a more researchintensive field. The latter implies that the field is more and more expected to produce academic output ('knowledge') not only for the national context, but also as a contribution to the forefront of the international scholarly debate in educational sciences in general and teacher education in particular. This development of the field is reflected in a wide variety of organisational forms of teacher education, including departments or faculties of teacher education within universities, within university

\footnotetext{
${ }^{1}$ For a more detailed presentation of the project, see Introduction article in this special issue.
} 
colleges $^{2}$, or stand-alone, specialized teacher education institutions. Inside universities and university colleges, teacher education has been organized in various ways. This ranges from a special teacher education faculty or department where all research and teaching activities in teacher education are the responsibility of one faculty/department, to a special unit in one faculty responsible for all education programmes and activities (with research being organised separately), to teacher education being organized jointly by various faculties within one institution, with the responsibility for didactics/pedagogy concentrated in one faculty, and the research and teaching activities in the disciplinary substance areas (from mathematics to history) being the responsibility of the respective faculties and departments across the institution.

Teacher education has traditionally been organized within each national higher education sector as a professional education activity, with very limited research activities of the staff involved, implying also a relatively small number of full professors being involved in teacher education, as well as only a few PhD students doing their thesis work in the field. This has changed, especially in university settings, rather dramatically over the last 15-20 years. Teacher education has become much more integrated into the university, and is more and more governed, organized and funded like other academic fields and disciplines, with the growing expectation, if not demand, that teacher education has to become more research based. As a consequence, teacher education units face an important challenge in the need to strengthen the research orientation of their staff, while maintaining the quality, relevance and professional practice-orientation of their teacher education programmes. An additional challenge in this is the relative lack of basic research funds for teacher education, certainly at the European level. The three departments and units involved clearly indicated the need they felt to be successful in the competition for EU funding (H2020), while at the same time they are sceptical about the attractiveness of the EU research funding and the difficulty to be successful in, for example, the competition for funding from the European Research Council (ERC) ${ }^{3}$. Consequently, the balance between 'research excellence' and relevance has another meaning in these units than in other departments in their universities. This reality, however, is difficult to 'sell' in the current research university with its strong, uniform emphasis on the need to be successful in 'excellence' research funding programmes ${ }^{4}$.

In this article our starting point is the enhanced institutional autonomy and the consequent change dynamics in the involved teacher education departments and units. We will focus especially on certain aspects of the departmental organisation and governance structures, within their specific university and national contexts. The underlying Flagship study is not an evaluation of the functioning or performance of

\footnotetext{
${ }^{2}$ University college is the English name used for Norwegian høyskoler, and their equivalents in other countries involved in the Flagship project, such as hogeschool (Flanders and the Netherlands), Fachhochschule (Germany, Austria and Switzerland), and ammattikorkeakoulut (Finland). A name used regularly internationally for these type of higher professional education institutions is university of applied sciences.

${ }^{3}$ None of the staff members of the three teacher education departments/units involved in the flagship project had until now been successful in applying for an ERC grant.

${ }^{4}$ The Board of UiO has e.g. in 2015 decided that the volume of externally research funding has to increase with $60 \%$. This applies mainly to H2020 funding.
} 
the involved departments, nor is it aimed at finding "best practices". Instead we will discuss relevant recent developments in the main areas we have focused on, challenges the departments face in their change processes, and the main similarities and differences among them.

The three universities involved differ from each other regarding the organisational design of teacher training. At the University of Oslo, most of the teacher training is concentrated in one department within one Faculty. At the University of Helsinki, elementary school teacher education is concentrated in one department within one Faculty, but subject teacher education takes place mainly in the Faculty responsible for providing instruction in these subjects. However, it is coordinated by the Department of Teacher Education in the Faculty of Behavioural Science. At the KU Leuven, teacher education is located in an independent centre within the Faculty of Psychology and Educational Sciences.

The presence of degree programmes in teacher education can be seen as a result of two slightly different developments. Formal sub-organisations, such as departments, intra-departmental units and study programmes are part of the university organisation. Usually teaching and student affairs have been more formalised than issues relating to research. This development is especially the case in the Nordic countries due to increased regulation and professionalisation of student administration from the 1980s onwards (e.g. Aarrevaara, Dobson and Wikström, 2015). Another development is part of the increasing competition between disciplines and their sub-disciplines within higher education. In this competition it is of importance in ensuring prestige and representation within the formal university organisation (Olson and Slaughter, 2016).

This article focuses on the interaction between external stakeholders and internal practices of departments (and other relevant units) of teacher education at the Universities of Oslo in Norway and Helsinki in Finland and KU Leuven in Belgium. We will start with briefly presenting the main governance and organisation structures of the departments and units involved at the three universities, followed by an discussion of a contingency perspective. The latter will be used in our analysis of the empirical Flagship project data. At the end of the article we present a number of relevant conclusions.

\section{Departmental governance and organisation}

\section{University of Oslo: Department of Teacher Training and School Research (ILS)}

The Department of Teacher Education and School Research (abbreviated in Norwegian as ILS) is one of the three departments at the Faculty of Educational Sciences, University of Oslo (UiO). The leadership is formed by a team, led by the head of department (HoD). Next to the HoD, who has the day-to-day responsibility in all department matters (academic and administrative) one of the other members is responsible for research matters, one for education matters, while the head of administration is the fourth member. Currently the person responsible for research matters is the first deputy head, while the person responsible for education matters is the second deputy head. The department has a board, consisting of the HoD, the first 
deputy head, two representatives of permanent academic staff and one of temporary academic staff, one representative of technical-administrative staff, and two student representatives. In addition to this formal governance structure, the department has a number of advising councils, including a programme council for educational matters.

The governance and organisation structure of the department has become quite complicated the last years. This started in 2006 with the establishment of research groups by the Faculty of Educational Sciences. Currently four of the Faculty's 10 research group are hosted by ILS, some of which have members also from the other departments of the Faculty. In addition, the department hosts one special research unit, the Unit for quantitative analysis in education (EKVA). Finally, the department hosts a Center of Excellence in Education, called The Centre for Professional learning in Teacher education (ProTed), which is a cooperative project by the Universities of Oslo and Troms $\emptyset$. This growing complexity of the governance and organisation structure of the department creates a number of coordination challenges that until now have been handled mainly informally.

\section{University of Helsinki: Department of Teacher Education}

The Department of Teacher Education (DTE) is one of two departments at the Faculty of Behavioural Sciences, University of Helsinki (UoH). In addition to the two departments, the Faculty is responsible for two so-called training schools at lower and upper secondary education level. The university sector in Finland has undergone a major reform resulting per 1 January 2010 in enhanced institutional autonomy, new institutional governance structures, and a new legal status for university personnel, who no longer are state civil servants. The change in the governance structures means a shift from a collegial to a more 'professional' or executive, hierarchical form of governance. The national changes in the university sector form an important frame of references for the understanding of the current governance model in DTE.

The department provides studies in six areas of teacher education, that is: class teacher education; Craft Science and Textiles teacher education; Home Economics and Home Economics teacher education; Kindergarten teacher and early childhood education; Subject teacher education; and Special education. The departmental research is organized four research units: Subject education; Teaching and learning; Education, culture and arts; and Special education.

The department leadership is formed by the head of department (HoD), who has selected three deputy heads - academic affairs, research, and working environment and community relations. The department board is chaired by the head of department and consists of professors', academic staff, and students' representatives. Other governance bodies are the study program development groups, the international affairs and education export committee, the academic affairs committee, the research affairs committee, the work environment and network affairs.

While this formal structure is important in the governance relationship between department, faculty and university, the main coordination and co-decision body is the department management group, also referred to as the steering committee. This body was introduced by the HoD in 2010 and consists of the formal leadership group plus 
all senior staff with an academic leadership position either of educational programmes or research groups and units. This group, which meets once a month forms in practice the main internal governance body of the department.

\section{KU Leuven: Centre for Educational Effectiveness and Evaluation}

The Catholic University of Leuven (KU Leuven) is organized differently than the Norwegian and Finnish universities. It consists of three so-called Groups, that is, the Humanities and Social Sciences Group, the Science, Engineering and Technology Group, and the Biomedical Sciences Group. The Faculty of Psychology and Educational Sciences is part of the Humanities and Social Sciences Group, together with six other faculties, the Institute of Philosophy, and the Group doctoral school. This Faculty is responsible for the educational activities in the area of teacher education. In addition, the Faculty hosts a large number of research groups, including those units responsible for research undertaken in the area of teacher education. The main research unit for teacher education is the Education and training research unit, which, is involved in, but not responsible for the educational programmes in teacher education, since it has in practice only a research coordination role. The two main research units in the of area teacher education are the Centre for Educational Effectiveness and Evaluation, and the Centre for Educational Policy and - Innovation and Teacher Training.

In practice the separate organising and governing of education and research in the area of teacher education reflects the recent tradition of KU Leuven to 'protect' and stimulate its staff's research activities. However, the rectorate has recently introduced a new education vision called 'the future self'. The aim is to strengthen the organisation and quality of the study programmes at KU Leuven through a more student centred teaching and learning approach.

\section{The contingency perspective}

Increasing demands for openness and transparency are a major concern for publicly funded universities. Dynamic, accountable and transparent governance is the starting point for handling these demands, and they are supplemented by a 'steering by information' approach. This is of growing importance alongside matters related to budgetary control and regulation. However, higher education policies and practices are adapting to societal changes under volatile conditions in the 2000s. As a result, the quality of education and research together with changes in operating cultures are factors that universities use to cope with uncertainty. At the heart of universities' management there is a need to create value by transformation, and by taking into account the effects of performance.

The analytical perspective for this article is anchored in contingency theory, assuming that external conditions will at least partially determine the internal structure and practices of organisations. We pay attention to teacher education departments' or units' relationships to other units and stakeholders and the nature of their external environment (Burke 2014). Our starting point is that adaptation to changes in the operating environment can arise from the internal capacity to improve performance. 
This means, for example, a willingness to reach excellence in research and a number of strategic decisions to improve the performance in teaching and research. At the same time, there is a risk for actors in accepting a compliance culture when organisations adopt policies to develop, describe, and implement their activities in external terms and the criteria generally assumed to be of importance by external actors.

Empirical evidence has been drawn from data analysis from three teacher education units at the three involved flagship universities The data gathering work includes 20 interviews with academic and administrative staff of the three involved universities. The analysis of these empirical data has been conducted through a focus on content regarding key words and themes of stakeholder, interaction, societal and society.

Contingency factors have an influence on the conditions of the organisation. They form a match between a solution and its context. In this case, the level of external stakeholders' participation in planning, decision making and implementation of core functions of teacher education departments and units is such a contingency factor. The empirical data analysed include information on stakeholders in decision making structures at universities, for example, members of university boards or stakeholder bodies targeting curriculum design and research themes. In addition to this, flagship universities are under the influence of their own and government regulations and decisions, which in general allow for a certain autonomy when it comes to taking care of relationships with important stakeholders in their environments. These universities are also affected by competitive research funding conditions.

\section{Contingency factors for teacher education departments}

External stakeholders are not formally represented in the governance bodies of departments responsible for teacher education study programmes at the three universities. These departments may instead have individual staff members or bodies responsible for societal interaction with representatives from, for example, labour unions and employers for teachers.

At the same time, it can be argued that some of the study programmes in the second decade of the $21^{\text {st }}$ century and reforms of older study programmes are results of recent interactions between universities and their external stakeholders. For instance, the Swedish speaking study programme for teacher education at the University of Helsinki was initiated on the basis of feedback and financing from Swedish speaking foundations and bilingual- and Swedish speaking municipalities in Southern Finland. This study programme started in 2016. Its preparations began some years earlier partly because of initiatives from these foundations and municipalities. Another example on adaptation to external contingents from the University of Helsinki's Department of Teacher Education, is the teacher training programme for multicultural school classes. In most universities, multicultural issues in teacher training have been integrated to the ordinary teacher training programmes. However, in the case of teacher training at the University of Helsinki, the multicultural teacher training is a separate programme because of funding reasons. The Department of Teacher Eeducation decided to apply 
for funding earmarked by the central administration of the University of Helsinki for strategic development projects. One of the projects that received this kind of funding was aimed at the development of a separate multicultural teacher training programme.

The analysis has been based on four identified contingencies. The first contingency is strategy, which has been used to describe the highest degree of diversification and to describe the relative autonomy and influence the staff has with respect to strategic decisions. The second contingency is external impact to influence the performance in teacher education units. In particular, the interviewees described the impact of the adaptation of external practices. The third contingency is external funding, that describes the interaction between the functions of research, teaching and societal impact in the teacher education units and the external stakeholders' impact on these functions. The fourth contingency is the culture of coping with uncertainty.

\section{The Analysis}

\section{Strategy}

In the three universities involved, the institutional strategies are aimed at improving the status of teacher education by the use of different interlinked measures aimed at improving the core tasks of the departments or units in question. However, there are different strategies among the involved universities when it comes to educational activities as well as research. The strategic plan at the University of Oslo defines the prioritised research areas, but at KU Leuven, the strategy is more opaque according to those who were interviewed. At the University of Helsinki, academic leaders are responsible for managing research, teaching and community relations, in conjunction with the staff, in accordance with the Strategic Plan of the University and the teacher education department's action plan. From this point of view, it seems that at the University of Helsinki, the strategic planning is primarily a top-down process.

For all of these departments and units of teacher education, one of the core educational goals is to operate on the basis of research-based knowledge. The number of high quality master's degrees completed by students is intended to be increased through a variety of measures, such as stronger leadership of education or focusing the resources to the strategy. At the University of Oslo, a primary strategic tool is the recruitment of master's students. However, according to the interviewees, the direction has not been very clear. A change from university-level strategic influence to strategic influence at the department level can be observed in Oslo (that is, towards the departmental board):

At this time, we have tried to develop a strategy that we can operate here at the department level, a strategy described in only five pages... We have simplified it so that it is possible to lead the department on the basis of this strategy. 
At the University of Helsinki this has been enhanced by strengthening master's degree thesis supervision, as the number of graduates is an identified bottleneck for the strategy. In interviews, it was indicated that the goal has not been discussed sufficiently in the planning phase of the strategy. An interviewee from the University of Helsinki describes the interaction between the university level and the department level in the strategy process as follows:

We communicate a lot about the aims of the strategy, the strategy has been developed, and there's a long process. Of course, much of this was coming from university side, this structure and the big picture. But we spend a lot of time discussing what we take to be the strategic aims.

Academic, University of Helsinki

In the KU Leuven strategic plan, the strategic goal in education is described in the portfolio activities. An interviewee from Leuven expresses his/her notions of a nonstrategy at the teacher education unit:

The research centre does not really have a strategic plan. It is not spoken about. We are educational evaluation researchers - and that is it.

\section{Academic, KU Leuven}

It seems that all three universities are emphasising the importance of their institutional strategic plan as first and foremost in guiding the university's own internal organisation. Their strategies can increase the differentiation between core functions and integration of different units in the organisation. In the interviews, there were surprisingly few ingredients through which the strategy is hoped to make a difference in the operating environment and to have an impact on conditions of departments of teacher education.

\section{External impact to influence performance}

When identifying contingency factors, particular attention was given to the extent to which external stakeholders are participating in planning, decision making and implementation. Based on the interviews, it seems that the external stakeholders' influence is based more on external pressures, such as performance measures. The interviews refer to attempts by external stakeholders to guide their department or unit directly in general as negative, even though some interviewees also express possible positive sides of these attempts.

Pressures of performance management emanate from inside the universities, from those responsible for university leadership and also horizontally as reciprocal interdependence among departments. In the interviews, there are descriptions of dependency between departments, but also the external influence against the will of the core of the unit's choices. The reciprocal interdependence between the units at the university has been described as follows 
Basically, I would say that from not having a lot of research on teacher education in the past in Norway, it has now intensified. I think this is a kind of mutual influence on the department [as academic unit] and the centre that we have now placed more emphasis on research on teacher education. And yes, I think this is a mutual reciprocal kind of development ...So I think everybody realised that we need to build a knowledge base on teacher education, so I think that is one very important influence at the promises of strategy.

Academic, University of Oslo

In the interviews there are themes, which are present in the discussions between the departments and the universities' management. These discussions dealt with the core duties and quantitative indicators associated with them.

A lot what they discuss about is about the number of teachers requiredhow many history subject teachers they will need or will they need more special education teachers- like that kind- they try to effect on how many and which kind of students we educate. So with these kinds of things it is not easy, of course.

Academic leader, University of Helsinki

Of course, we have inter-department teacher education so I think that our relevance is relying on the teacher educating component in the collaboration.

\section{Academic, University of Helsinki}

Vertical discussions between university leadership and departments are connected with academic and administrative commitments, such as the results of the performance negotiations. But discussions between the horizontal units are on a range of topics as they are based on academic commitments and social commitments.

These days the research groups have lunches together to get to know each other but in fact the research groups are still 'stand alones'.

Academic, KU Leuven

\section{External funding for core functions}

The impact of external stakeholders is seen most clearly in the respondents' perceptions of the importance of external funding in research. On this issue there are important differences between the universities involved. This is reflected, for 
example, in the teacher education department's or unit's relative freedom to decide on the use of external funding:

On the other hand, the centre cannot take this year's money to the next year; it has to be spent [this year]. At the same time, it is possible to build reserves and to use these reserves. The university cannot touch these, although they have tried. The university keeps the interest generated by the reserves. The reserves are used 'strategically'.

Academic, KU Leuven

External financing is also an opportunity to bring content and resources for the universities' societal impact. This is reflected in the respondents' description of the use of time.

Research means that I do teaching based on research: supervise doctoral students, apply for funding for projects and implement them and report on the outcomes, particularly for the Flemish government. I teach a number of courses, both at the bachelor's and the master's level - teacher training as well as pedagogical sciences. And societal services means that professors should engage in public debate, to vocalise expertise for instance with respect to educational reforms. The difficulty is to make a time distribution between the three functions. Depending on which week it is, I would say: teaching, 40\%, research 50\%, and community outreach $10 \%$.

\section{Academic, KU Leuven}

External funding is important not only for the funding as such, but also in aiming to develop the organisational culture.

This is very important for supporting that field, and then people are working together in writing applications, more and more we are emphasising that. We cannot make it alone so we have to make it together. Our vice head who is responsible for research, also has to read the applications and give feedback.

Academic leader, Helsinki

\section{Coping with uncertainty}

The fourth contingency factor is uncertainty, which is caused by dependence on internal and external factors. In this article strategy and external impact represent sequential interdependence referring to an output from one activity being the input to the next (Bankvall et al. 2010). This generates units and determining obligations by defining their tasks in traditional ways (Waes et al. 2016). The ability to manage external funding represents the reciprocal interdependence with reasonable rules and 
by providing them, the units can influence their own future. In the interviews, the rules are seen rather as redundant factors than as a capacity to enhance the performance (Peters 2001). The uncertainty is directed above all to governance, strategy and funding as illustrated by the following quotes:

Uncertainty with governance:

On the one hand, you have the faculty and on the other hand the research groups. Some people argue that the faculty should not be engaged with research. If there are people attached to research units, and the research units receive a budget, then they argue that they should deal with the rules and budget and not the faculty. Others argue that the faculty level is important because it makes them stronger. Those research units are engaged in teaching, research and community outreach. There is disagreement about that.

Academic, KU Leuven

Uncertainty with strategy

So, it affects my work in the sense of more administration and more secretarial functions. I would prefer that to be done in another way so they could take something from my shoulders or insist on this actually [happening].

Academic leader, University of Oslo

Uncertainty with funding

I try to encourage people in my unit to go for European Research Council (ERC) grants. Framework funding is another cup of tea, that involves a lot of bureaucracy.

Academic, University of Oslo

As can be seen in the three citations above, the responses on the core tasks are also discussed in terms of uncertainty. In this case, it is directed to support services and the possibility of using the research services of the university. At the same time, an interviewee also indicated the uncertainty of their own knowledge. This is typical of criticisms of external funding instruments that came out of the interviews. Increasing the resources for core tasks by external funding is treated with suspicion in many responses:

I think that the demands to have funding from outside the university have increased incredibly. And I think that from the longer period-if I think about it-it has been affecting teacher education very much. In particular it's really difficult to get funding from the Academy of Finland or from the European Union. Maybe more often EU project, but they are not always research focused. But, how can you say it: It has changed the culture and the culture of this- somebody said academic capitalism-has 
become such that in a way that you need to write review articles and so on and so on. It becomes sort of competition but also the university or department has to provide support- help people to become part of this, not competition, but to help them to get funding.

Academic leader, University of Helsinki

Uncertainty is a factor, which is caused by external changes, changes in society and changes inside the academy. This view was clearly expressed in the interviews in the three universities' departments and units for teacher education. However, the differences between these three universities are related to the direction of interactions. The departments and their staff can cope with the uncertainty by strengthening the external relations such as strengthening stakeholder interaction, societal interaction functions, or by increasing the external funding. In the universities involved, this takes place first of all in the KU Leuven. Another option is to establish horizontal relationships, such as reciprocal interactions between the academic units or closer interaction between the support services and academic departments, as is the case in the Universities of Oslo and Helsinki. The uncertainties in governance structures are contingents because the staff has to adapt themselves to these structures. For instance, staff members need to know if there is a formal structure for development discussions with the head of the department or should these discussions be conducted, for example, with a dean of the faculty.

\section{Conclusions}

In this article, the resource variable has been used to describe and interpret difference in performance focus (Bouckaert and Halligan 2008). The University of Helsinki is characterised by sequential interdependence between units, which means dependence on outcomes and simultaneously competition for resources between the performance units. Success will require horizontal cooperation, but the rules of the game between the departments are determined at the university level. This is due to the fact that the importance of performance management is less than at the other universities involved. In the interviews at KU Leuven and the University of Oslo there was more reflection on reciprocal interdependence, emphasising horizontal practices and the common rules of the game.

One of the more important contingent factors we found was the transformation of governmental funding instruments. However, respondents from all three universities expressed uncertainty about how the external influence and external funding will build effectiveness or strength into basic tasks of research and education in the departments and units of teacher education. The funders of higher education, which at the three examined universities are mainly governmental public actors, together with other stakeholders, both internal and external, have had a profound effect on teacher education, including an evolution of it into a more research-oriented field. Scholars in teacher education are supposed to contribute both to the national context and to 
publish internationally. The scholars are encouraged to network internationally and contribute to the global knowledge production.

It can be concluded on the basis of the Flagship project data that the increasing relevance and importance of the academic field of teacher education for national education systems is reflected in the governance arrangements for teacher education. Also the increasing emphasis on international excellence, cooperation and competition in research is effecting the working culture and the governance practices at teacher education departments and units.

\section{References}

Aarrevaara, T., Dobson, I.R., and Wikström, J. (2015) Changing Employment and Working Conditions. In: Fumasoli, T. et al. (eds) Academic Work and Careers in Europe: Trends, Challenges, Perspectives. Dordrecht. Springer, pp. 95-115.

Bankvall, L., Bygballe, L.E., Dubois, A. and Jahre, M. (2010) Interdependence in supply chains and projects in construction. Supply Chain Management - An International Journal, Vol. 15(5), pp. 385-393.

Bouckaert, G. and Halligan, J. (2008) Managing Performance - International Comparisons. London: Routledge.

Burke, W.W. (2014) Organization Change - Theory and practice, $4^{\text {th }}$ ed. Thousand Oaks, CA: Sage Publications.

Olson, J., and Slaughter, S. (2016) Nordic Higher Education Internationalization: The New Bildung Or A Prestige Economy? In: Cloete, N. et al. (eds) Pathways Through Higher Education Research: A Festschrift In Honour Of Peter Maassen, Oslo: Department of Education, University of Oslo.

Peters, B.G. (2001) The Future of governing, $2^{\text {nd }}$ ed. Lawrence KS: University Press of Kansas.

van Waes, S., Moolenaar, N.M., Daly, A.J., Heldens, H.P.F., van Petegem, P, and Van den Bossche, P. (2016). The networked instructor: The quality of networks in different stages of professional development. Teaching and Teacher Education Vol. 59, pp. 295-308. 